\title{
World's Food Research Experts Gathered at II International Conference on Food Chemistry \& Technology (FCT-2016)
}

\author{
Mun YhungJung \\ College of Food Science, Woosuk University, Republic of Korea
}

"Correspondence to:

Mun Yhung Jung, $\mathrm{PhD}$

College of Food Science, Woosuk University

Samnye-eup, Wanju-gun

Jeonbuk Province 565-701, Republic of Korea

Tel: 82-63-290-1438

Fax: 82-63-291-9312

E-mail: munjung@woosuk.ac.kr

Received: November 29, 2016

Accepted: December 08, 2016

Published: December 09, 2016

Citation: Jung MY. 2016. World's Food Research Experts Gathered at II International Conference on Food Chemistry \& Technology (FCT-2016).J Food Chem Nanotechnol 2(4): 168-169.

Copyright: () 2016 Jung. This is an Open Access article distributed under the terms of the Creative Commons Attribution 4.0 International License (CC-BY) (http://creativecommons.org/licenses/ by/4.0/) which permits commercial use, including reproduction, adaptation, and distribution of the article provided the original author and source are credited.

Published by United Scientific Group

\section{Meeting Report}

The second edition of International Conference on Food Chemistry \& Technology concluded successfully on November 16, 2016 at Hampton Inn Tropicana and Event Center, Las Vegas, NV, USA with a focus on current and future challenges in food research.

II International Conference on Food Chemistry \& Technology (FCT-2016) organized by United Scientific Group, USA; gathered together the senior level experts with a perfect blend for multidisciplinary collaboration between young researchers, education scientists, technologists and food industry representatives from all over the world focusing on latest technological developments in the food research.

FCT-2016 featured Prof. Dennis R. Heldman, The Ohio State University, USA as plenary speaker delivering on Optimizing the design of preservation processes. Dr. Heldman is an internationally well-known food engineer. $\mathrm{He}$ served as president of the Institute of Food Technologists during 2006-2007.

Workshop on "Advanced food technologies: thermal and non-thermal" organized by Dr. Wenjie Liu, General Mills, USA was the highlight for the event.

\section{FCT-2016 rendered presentations on:}

Food Chemistry: Chemical and enzymatic reactions, bioactive constituents, micronutrients, food additives, and ingredients, food oxidation and antioxidants, food structure, flavor and quality, food processing \& packaging technologies, and functional foods and functionality.

Food Analysis: Food safety and control, analytical methods for food components, authenticity and integrity of food, food fortification and nutrition, food toxicology and food allergy, microbiological and biochemical aspects of food, food hydrocolloids, and food supplements and food labels.

Food Technology: Food technology and dairy science, food and agriculture biotechnology, nanotechnology in food, food engineering, food rheology and shelf life, and recent trends in food science \& technology.

\section{FCT-2016 Conference Report}

In the beautiful city of Las Vegas, the opening day of the conference (November 14, 2016) started with the inauguration by Prof. Mun Yhung Jung, Editor-in-Chief, Journal of Food Chemistry and Nanotechnology. And the session started with Prof. Dennis R. Heldman, The Ohio State University, USA, plenary talk on "Optimizing the design of preservation processes". Prof. Mark Failla, The Ohio State University, USA, delivered the second keynote of Day 1 on "In vitro models for cost-effective screening of the bioaccessibility and bioavailability of health promoting compounds from foods and ingredients". Prof. 
Sam K. C. Chang, Mississippi State University, USA, gave a keynote presentation on "Changes of soybean biochemical components and food quality as affected by post-harvest storage conditions". Fourth keynote presentation by Prof. Elizabeth H. Jeffery, University of Illinois, USA, delivered on "A new era for prebiotics: Improving activation of bioactive food components by the microbiome" and final keynote talk on Day-1 ended with Prof. Mun Yhung Jung, Woosuk University, South Korea, delivered on "A novel highly-sensitive inorganic arsenic speciation in rice by a gas chromatography coupled to tandem mass spectrometry in combination with one step derivatization technique".

After the keynotes, the session continued with the quality speaker presentations on the topics Food Chemistry: Chemical and enzymatic reactions, bioactive constituents, micronutrients, food additives, and ingredients, food oxidation and antioxidants, food structure, flavor and quality, food processing \& packaging technologies, and functional foods and functionality. And with a special workshop on "Advanced food technologies: thermal and non-thermal" by Dr. Wenjie Liu, General Mills, USA the first day of scientific meeting finished.

Second day of the conference (November 15,2016) started with the Dr. Martin Buehler, Decagon Devices, Inc, USA, keynote talk on "Glass-transition boundary curve for shelflife prediction”. Prof. Isabel M.P.L.V.O. Ferreira, University of Porto, Portugal, delivered the second and final keynote of Day2 on "Reduction of cancer risk related to the consumption of red meat". After the keynotes, the session commenced with the quality speaker session on Food Analysis: Food safety and control, analytical methods for food components, authenticity and integrity of food, food fortification and nutrition, food toxicology and food allergy, microbiological and biochemical aspects of food, food hydrocolloids, and food supplements and food labels, and followed by Young Researchers Forum then ended with Poster presentations.
The last day of the conference was mainly focused on Food Technology: Food technology and dairy science, food and agriculture biotechnology, nanotechnology in food, food engineering, food rheology and shelf life, and recent trends in food science \& technology. FCT-2016 finally concluded with the closing ceremony and certificate distribution.

USG is obliged to the committee members, speakers and delegates of FCT-2016 for their outstanding support and participation.

\section{Conference Proceedings}

All accepted conference abstracts will be published in Journal of Food Chemistry and Nanotechnology (JFCN), a unique, peer-reviewed, open access journal covering food chemistry along with food nanotechnology, a newly evolving sector in the food science field. In addition, full text papers will also be considered for the journal upcoming issue.

JFCN is driven by active researchers in the field: (Prof. Mun Yhung Jung, PhD; Woosuk University, South Korea), as Editor-in-Chief; and our esteemed Editorial Board, who help ensure articles meet the high standards required for publication.

The journal will publish four issues a year, and will include key data, original research, short communication, mini- or comprehensive review papers, letters, and critical commentaries relating to food chemistry and food nanotechnology covering bioactive constituents and micronutrients, antioxidants, food flavor, active-packaging techniques, nanosensors for detection of contaminants and toxins, nanoencapsulation, nanofiltration, food safety and toxicology, enzymatic and microbial changes of food properties, quality control and assurance, nutrition, engineering, and analytical methods. 